\title{
NIR prediction of fruit moisture, free acidity and oil content in intact olives
}

\author{
Por José Antonio Cayuela ${ }^{{ }^{*}}$, José María García ${ }^{1}$ and Nuria Caliani ${ }^{2}$ \\ ${ }^{1}$ Department of Physiology and Technology of Plant Products. Instituto de la Grasa (CSIC). \\ Avda. Padre García Tejero, 441012 Seville, Spain \\ ${ }^{2}$ Escuela Universitaria de Ingeniería Técnica Agrícola, Universidad de Sevilla Crtra. de Utrera, \\ Km 1. Seville 41013, Spain \\ ( ${ }^{*}$ Corresponding author: jacayuela @ ig.csic.es)
}

\section{RESUMEN}

Predicción NIR de la humedad del fruto, acidez libre y contenido de aceite en aceitunas intactas.

En este trabajo se ha investigado la predicción de parámetros de calidad de aceitunas y de aceite de oliva virgen mediante medidas directas en el fruto de espectrometría de infrarrojo cercano (NIRS), evaluándose la utilidad de un espectrómetro portátil. Se han desarrollado respectivamente modelos predictivos y calibraciones utilizando como análisis de referencia tanto la extracción de aceitunas individualmente con hexano-isopropanol, como la extracción de pasta de aceituna mediante Soxhlet. Los parámetros analizados fueron: acidez libre del aceite, rendimiento de la extracción física de aceite, contenido de aceite referido a peso fresco, contenido de aceite referido a materia seca y humedad del fruto. Los resultados indican un buen potencial de predicción mediante ambos métodos y alientan al perfeccionamiento de los modelos obtenidos mediante la ampliación de las calibraciones. Los modelos predictivos de la humedad del fruto mostraron una alta precisión.

PALABRAS CLAVE: Aceite - Aceituna - Acidez - Humedad-NIR.

\section{SUMMARY}

NIR prediction of fruit moisture, free acidity and oil content in intact olives.

In this work, the prediction of olive fruit and virgin olive oil quality parameters through the direct measuring of the fruit using near infrared spectrometry (NIRS) has been investigated and the effectiveness of a portable spectrometer has been assessed. Models and calibration tests were developed using both the hexane-isopropanol extraction of individual olive fruits, and the Soxhlet extraction of olive paste. The parameters analyzed were the free acidity in olive oil, oil yield from physical extraction, oil content referring to fresh weight, oil content referring to dry matter and fruit moisture. The results indicate a good predictive potential with both methodologies and serve to encourage improvement in the obtained models through the enlargement of the calibrations. Fruit moisture prediction models showed high accuracy.

KEY-WORDS: Acidity - Oil - Olive - Moisture - NIR.

\section{INTRODUCTION}

An accurate selection of the optimal harvesting date for mill olives is very important, because oil quality depends largely on it (García et al., 1996). Therefore, it would be useful to develop techniques for monitoring oil content during maturity stages, by measuring the olives directly on the tree. Likewise, once in the mill, it would be advantageous to classify the fruits according to their oil content, oil yield and fruit moisture prior to oil extraction. This would improve the management of the extraction process and would allow a rapid calculation of payment to the grower according to these parameters.

The free acidity value in olive oil is one of the key parameters for its classification into the different levels of commercial quality categories. Therefore, the prediction of this parameter from measurements on intact olives would be beneficial to the olive oil industry.

Although the use of Near Infrared Spectroscopy (NIRS) for determining the internal quality parameters of intact fruit was investigated during the 80's, its industrial application has not begun until now (Nicolaï et al. 2007).

In intact fruit, NIRS has been used mainly to make a non destructive determination of the soluble solid contents (SSC) in apples (lyo and Kawano, 2001; Hernández et al., 2003; Zude et al., 2006), citrus fruits (Tsuchikawa et al., 2003; Guthrie et al., 2005; Hernández et al. 2006; Kawano et al., 1993), peaches (Slaughter, 1992; Peiris et al., 1997), cherries (Lu, 2001) and melons (Dull et al., 1989; Dull et al., 1992; Ito et al., 2002; Guthrie et al., 2006).

With regard to the application of NIRS on olive products, the determination of oil content and humidity in olive paste is currently being used on a regular basis for routine determinations (García et al., 2005; Gallardo et al., 2005; Bendini et al., 2007). Furthermore, NIRS determinations of oil content and humidity in olive paste and olive pomace obtained comparable efficiency to already well established methodologies such as nuclear magnetic resonance and the Soxhlet extraction method (García et al., 2005; Conte et al., 2003; Muik et al., 2004; Gallardo et al., 2005). Previously, Hermoso et al. (1999) reported calibration coefficients for determining the oil content and the humidity of $R=0.96$ and $R=0.60$, respectively, in olive cakes resulting from the two phases oil 
extraction system, using NMR as the reference analytical method.

The applications of NIRS to olive oil and other oils has been the subject of a wider investigation. Galtier et al. (2007) successfully identified the geographical origin and composition of virgin olive oils through a chemometric analysis of the NIRS spectrum. Costa et al. (2008) determined acidity, refractive index and viscosity in corn, soybean, canola and sunflower oils using this technology. The results showed that for each parameter studied, the same predictive model was valid for the four types of oil. Mailer (2004) reported satisfactory predictions of free fatty acids, peroxide value, polyphenol content, induction time, chlorophyll and the major fatty acids composition of olive oil using NIRS. $R^{2}$ coefficients ranged from 0.86 to 1.00 and coefficients $1-\mathrm{RV}$, characteristic of predictive error, from 0.73 to 0.99 . Previously, Conte et al. (2003) developed applications for determining peroxide value, free acidity and oleic acid content in olive oil and the oil yield of olives, reporting results that were in line with those obtained from the official methods with the exception of peroxide value, which showed lower values. Likewise, the use of NIRS has been evaluated for quality control and the on-line classification of virgin olive oils, analyzing free acidity, bitter taste (K225) and fatty acid composition with interesting results (Jimenez et al., 2005). Moreover, the potential of NIRS to analyze adulteration in olive oil has also been tested (Downey et al., 2002; Wesley et al., 1995; Yang and Irudayaraj, 2001).

Information relating to the identification of chemical quantitative or qualitative parameters through NIRS using intact olives is scarce in the scientific literature. Leon et al. (2003) obtained regression models by partial least squares (PLS) and NIRS, with predictive errors sufficiently small, for the analysis of oil content $\left(R^{2}=0.83\right)$, moisture $\left(R^{2}=0.88\right)$ and fatty acid composition $\left(R^{2}\right.$ from 0.77 to 0.81 for oleic and linoleic) in intact olives, as a useful tool in olive breeding programmes. Finally, as part of an olive tree breeding program, the same authors (Leon et al., 2004) reported the influence of the parents and the harvest year, on oil content , moisture and fatty acids determined by NIRS analysis of intact olives, with the same calibration results as previously mentioned.

The objective of the present study is to determine the effectiveness of a portable NIR spectrometer for the prediction of oil free acidity, oil yield, oil content in fresh fruit, oil content in fruit dry matter and fruit moisture content, using PLS models and analyzing intact fruits.

\section{MATERIALS AND METHODS}

\subsection{Olives}

The calibration for the prediction of free acidity (FA) (Set A) was carried out using a $20 \mathrm{~kg}$ batch of olives (Olea europaea cv. Picual) from Mengíbar (Jaen). This batch was composed of olives in a wide range of maturity. The olives in a similar maturity stage were grouped and divided into 300-350 g samples, which were the sample unit. The predictive calibration of the humidity and oil content using the hexane-isopropanol method as the oil reference analysis (Set $B$ ) was carried out on two lots of 60 'Picual' olives harvested in Dos Hermanas (Sevilla), with the sample unit being the individual fruit. Another calibration was conducted for the prediction of moisture and oil content with 'Arbequina' olives also from Dos Hermanas (Sevilla), using the Soxhlet method as the oil reference analysis (Set $\mathrm{C}$ ). For this purpose, a batch of $1400 \mathrm{~g}$ olives was classified by maturity stage into 14 samples of $100 \mathrm{~g}$, each constituting a sample unit.

\subsection{Spectral acquisition}

The acquisition of spectra was performed using a portable AOTF-NIR spectrophotometer (Luminar 5030, Brimrose Corp., Maryland), equipped with a reflectance post dispersive optical configuration and an InGaAs (1100-2300 nm) detector. AOTF technology presents, as its main advantage, the speed of the spectrum acquisition which is higher than that obtained with other technologies such as those based on Fourier transform, monochromators or other filters (McClure, 2003). The spectrometer includes a measurement unit or 'gun' and a computer unit. Furthermore, this device is equipped with a base for use in the laboratory, with a measuring rotary capsule. The spectrometer offers good portability, with $4 \mathrm{~h}$ autonomy through a set of batteries.

The acquisition of spectra was conducted according to the set of samples. For Set A (oil acidity), a representative spectrum of the sample was obtained by averaging the spectra of each individual fruit in each 300-350 g sample. Each olive fruit spectrum was obtained by acquiring 50 spectra around the fruit equator with continuous measuring configuration.

In the predictive calibrations of Set $B$, the acquisition of spectra was performed individually for each olive fruit, constituting the sample unit. The instrument was configured to obtain an average of 50 spectra, acquired along the equatorial circumference of the fruit.

Samples of virgin olive oil for the free acidity analysis were obtained from the Abencor Method. For Set C, the mean spectra of each $100 \mathrm{~g}$ olive sample was acquired using the measuring rotary capsule unit of the instrument, configured to obtain each measurement as an average of 200 spectra.

Briefly, each 300-350 g olive sample was ground in a mill, the resulting paste was introduced into a jar and weighed. Then it was beaten for 20 min after the addition of $10 \mathrm{~g}$ talc. Subsequently, $60 \mathrm{~mL}$ of water were added to the paste and it was beaten again for $10 \mathrm{~min}$ and then centrifuged for $1 \mathrm{~min}$ (3500 r.p.m.) to separate the solid residual. Finally, the supernatant liquid was introduced into a 
graduated tube, where the virgin olive oil was separated from the aqueous phase by decanting.

\subsection{Free Acidity Reference Analysis}

Free acidity (FA) was expressed as percentage oleic acid and analyzed according to the Official Methods of Analysis of the EC (EUC, 1991; 1997). Briefly, 4 to $6 \mathrm{~g}$ olive oil were weighed into $250 \mathrm{~mol}$ wide mouth Erlenmeyer flasks, 50-mol ethyl alcohol: ethyl ether 1:1 with a few drops of phenolphthalein added, and then neutralized with $\mathrm{NaOH} 0.1 \mathrm{~N}$ until pink in color.

\subsection{Oil Yield Reference Measuring}

Once decanted after centrifugation, the volume of oil was measured in the graduated tube and the oil yield $(Y)$ calculated as the ratio between the oil volume and the olive fruit weight from which it was obtained, considering that, the density of olive oil is $0.916 \mathrm{~g} / \mathrm{mL}$.

\subsection{Oil Content by Hexane: Isopropanol Extraction}

Following the acquisition of spectra, the olives were weighed and put in a stove at $110^{\circ} \mathrm{C}$ for $36 \mathrm{~h}$. After total water removal, the dried fruits were put in $50 \mathrm{~mL}$ airtight plastic pots. Once they reached room temperature, they were weighed again for determining the moisture content. After that, using a scalpel, the pulp of each dried fruit was separated and shredded inside the same plastic pots, ensuring a perfect homogenization of the sample. Approximately $2 \mathrm{~g}\left(10^{-4} \mathrm{~g}\right)$ of each dry sample were introduced into a $50 \mathrm{~mL}$ centrifuge tube, where 25 $\mathrm{mL}$ of a mixture of hexane: isopropanol (3:2) was added. Then, the tube was shaken for 2 min and the sample extracted for $30 \mathrm{~min}$. After that, $12.5 \mathrm{~mL}$ of a $1 \%$ solution of sodium sulphate were added, the tube was shaken again for $2 \mathrm{~min}$. and centrifugated at $3000 \mathrm{rpm}$ for $10 \mathrm{~min}$.

After centrifugation, the lipid-phase was separated with a Pasteur pipette and the solvent was eliminated in a rotary evaporator. The complete absence of solvent in the oil was assured by placing the flasks in a stove at $110^{\circ} \mathrm{C}$ for $2 \mathrm{~h}$. Finally, the oil content was gravimetrically determined for both fresh weight $\left(\mathrm{OCFW}_{\mathrm{B}}\right)$ and dry matter $\left(\mathrm{OCDM}_{\mathrm{B}}\right)$.

\subsection{Oil Content by Soxhlet Method}

Each sample of approx. $100 \mathrm{~g}$ olives was ground in the 'Abencor' mill and two replicates of approx. 40 g. were obtained from the resulting paste and then placed in capsules and dried in a stove at $110^{\circ} \mathrm{C}$ for $24 \mathrm{~h}$. The resulting dry material was weighed to determine fruit moisture, and extracted, using Soxhlet. Later, oil content was gravimetrically determined for both dry matter and fresh weight.

\subsection{Moisture content}

The olive moisture content was determined by gravimetry, considering the percentage of fresh weight that the difference between fresh and dried weight represents. According to the oil extraction system, two different sample units were used: when oil content was determined by hexane:isopropanol extraction, fruit moisture was determined in each individual olive fruit; and when Soxhlet was used, this parameter was determined in each $100 \mathrm{~g}$ olive sample.

\subsection{Chemometry and Calibration Procedure}

Oil free acidity and oil yield models were obtained from oil samples extracted by the Abencor system and the reference was analyzed for these parameters as previously indicated. Fruit moisture content and oil content models were conducted from reference determinations using individual fruit sample units. Calibration tests for both moisture and oil content were obtained from olive paste samples.

Partial Least Squares (Wold et al., 1983) models were always obtained with Unscrumbler (CAMO Software AS, Norway) with the full spectrum (1100$2300 \mathrm{~nm}$ ); analysis of the spectral significant variables was conducted on each model and calibration tests were made with the correspondent wavelength intervals.

Before the calibration, the spectral variation of the data was analyzed by Principal Component Analysis (PCA), which requires no laboratory reference values, using Unscrumbler software. The reflectance data was transformed to absorbance, mean normalized and treated by Multiplicative Scatter Correction (MSC) or first order Savitzky-Golay or Gap-segment differentiation. Standard Normal Variate Transformation (SNV) was always tested. In order to confirm the influence of pre-processing on the prediction of the calibration models, different combination of gap and smooth were tested for gapsegment derivatives. The models were optimized by outlier elimination. Full-cross internal validation (FCV) was always conducted for building models, and external validation exercises for the prediction using the corresponding models on completely independent samples were conducted.

The latent variables were selected for minimum standard errors of calibration (SEC); the performance for PLS procedure was assessed in terms of the correlation coefficient of calibration $\left(R_{c}\right)$, standard error of performance (SEP), and root mean square error of prediction (RMSEP).

\section{RESULTS AND DISCUSSION}

\subsection{Reference Analysis}

The values from the reference analysis are included in Table 1. As can be seen, a wide range of the parameters was revealed for Picual. Arbequina samples showed a smaller range for the parameters 
Table 1

Statistical data of the analytical quality parameters ${ }^{\text {a }}$

\begin{tabular}{|c|c|c|c|c|}
\hline \multicolumn{5}{|c|}{ CALIBRATIONS WITH ONLY INTERNAL VALIDATION } \\
\hline Calibrations & Samples & Range & $\sigma$ & $\overline{\boldsymbol{X}}$ \\
\hline \multicolumn{5}{|c|}{ Hexane:Isopropanol Method } \\
\hline Picual & & & & \\
\hline Fruit moisture & 120 & $48,75-68,11$ & 4,03 & 56,94 \\
\hline OCFW & 120 & $19,49-44,21$ & 5,10 & 29,17 \\
\hline OCDM & 120 & $33,85-68,88$ & 7,03 & 51,11 \\
\hline \multicolumn{5}{|c|}{ Soxhlet Method } \\
\hline Arbequina & & & & \\
\hline Fruit moisture & 14 & $58,05-63,55$ & 1,44 & 59,79 \\
\hline OCFW & 14 & $16,32-17,84$ & 0,46 & 16,96 \\
\hline OCDM & 14 & $40,16-45,42$ & 1,89 & 42,29 \\
\hline \multicolumn{5}{|c|}{ Abencor Method } \\
\hline Picual & & & & \\
\hline Oil free acidity & 58 & $0,164-0,482$ & 0,07 & 0,25 \\
\hline Oil yield & 58 & $13,01-25,22$ & 3,01 & 20,23 \\
\hline \multicolumn{5}{|c|}{ CALIBRATIONS WITH EXTERNAL VALIDATION } \\
\hline Calibrations & Samples & Range & $\sigma$ & $\overline{\bar{x}}$ \\
\hline \multicolumn{5}{|c|}{ Hexane:Isopropanol Method } \\
\hline Fruit moisture & 90 & $48,75-68,11$ & 3,65 & 56,08 \\
\hline OCFW & 90 & $19,49-40,83$ & 3,95 & 27,69 \\
\hline OCDM & 90 & $35,03-68,88$ & 7,26 & 51,52 \\
\hline \multicolumn{5}{|c|}{ Abencor Method } \\
\hline Oil free acidity & 39 & $0,163-0,482$ & 0,08 & 0,25 \\
\hline \multicolumn{5}{|c|}{ SET OF SAMPLES OF EXTERNAL VALIDATIONS } \\
\hline Calibrations & Samples & Range & $\sigma$ & $\bar{x}$ \\
\hline \multicolumn{5}{|c|}{ Hexane:Isopropanol Method } \\
\hline Fruit moisture & 30 & $51,77-65,56$ & 3,97 & 59,82 \\
\hline OCFW & 30 & $22,35-44,21$ & 5,55 & 33,90 \\
\hline OCDM & 30 & $38,36-59,23$ & 6,07 & 49,72 \\
\hline \multicolumn{5}{|c|}{ Abencor Method } \\
\hline Oil free acidity & 19 & $0,175-0,349$ & 0,05 & 0,24 \\
\hline
\end{tabular}

${ }^{a}$ CG, contenido graso; $\sigma$, desviación típica; $\bar{X}$, media. OCFW, Oil content refered to fresh weight; OCDM, Oil content refered to dry matter.

analyzed, because of the higher homogeneity in the maturity state of the olives used.

\subsection{Spectral Variable Analysis}

The analysis of important variables showed that for almost all calibrations it was impossible to identify wavelength intervals with a decisive importance, showing the influence of virtually the entire spectrum. Over all, in the predictive calibration for virgin olive oil yield, those variables within the intervals 100 to158 nm and 213 to 294 $\mathrm{nm}$ were identified as the most influential.

\subsection{Free acidity-Set A}

The best spectral data pre-treatment in the calibrations to predict FA by NIR measurements in olive fruits was the transformation to absorbance and mean normalization. The coefficients of calibration $\left(R_{C}\right)$ and full cross validation $\left(R_{C V}\right), 0.89$ and 0.81 respectively, were significantly good at a prediction particularly difficult, since FA is a feature of the olive oil and not of the olive fruit. Likewise, the coefficients RMSEC and SEC were both aproximately 13\%, values close to $10 \%$, considered acceptable. The scattering of FA prediction is depicted in Figure 1.

An external validation exercise was conducted. With this purpose, a new calibration with two thirds of the available samples was held, using as validation set the 19 remaining samples. The statistical coefficients of this calibration as well as the error of prediction (RMSEP) and standard error of performance of the model (SEP) are included in Table 2.

\subsection{Olive Oil yield-Set $\mathbf{A}$}

Calibration tests were conducted for the prediction of $Y$ with intervals of $100-158 \mathrm{~nm}$ and 213-294 nm, which were highlighted by its influence on the analysis of important variables made for this parameter. However, the coefficients of calibration 


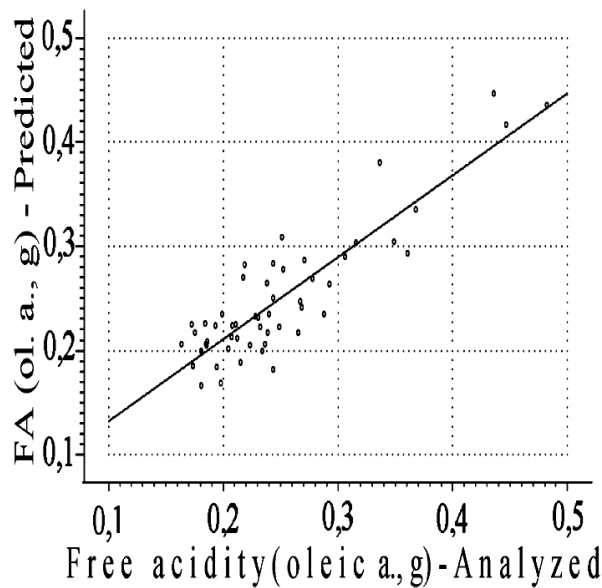

1

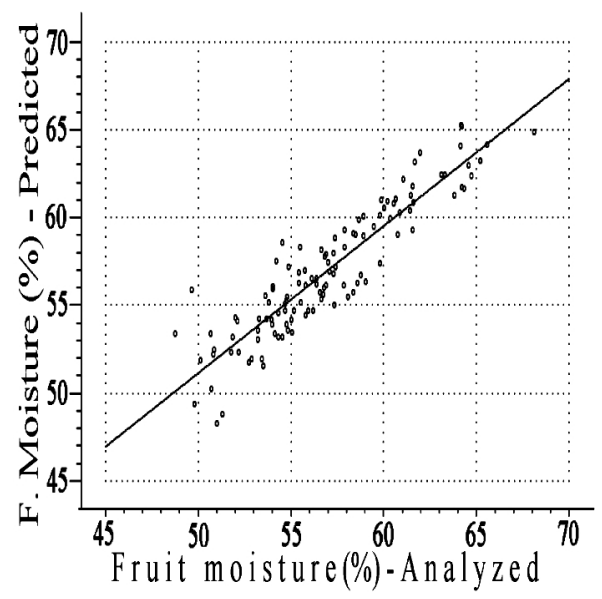

3

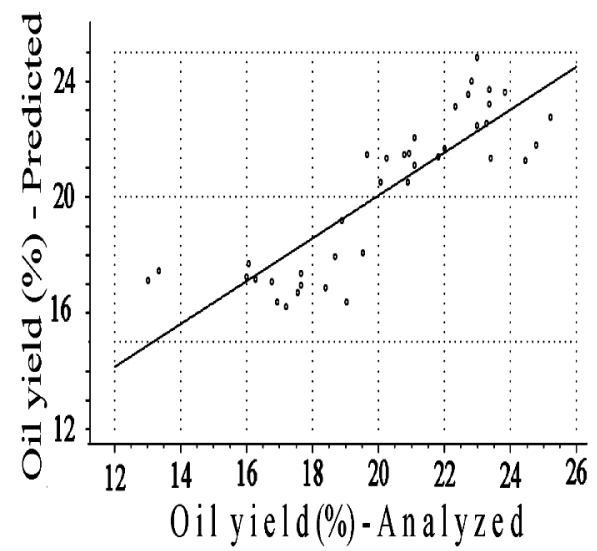

2

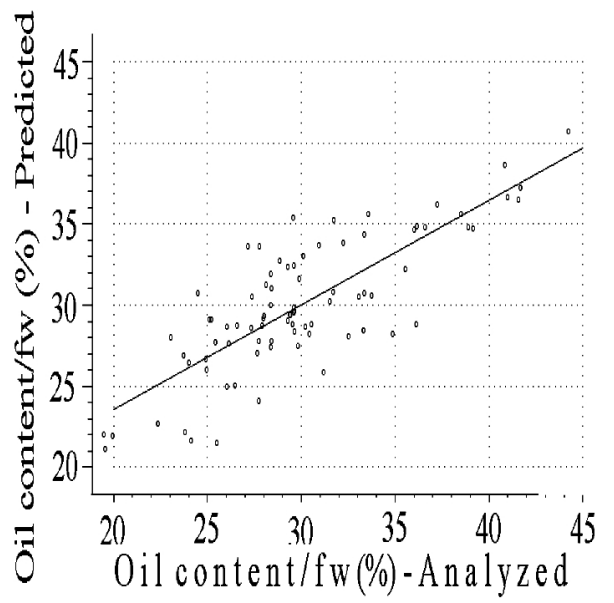

4

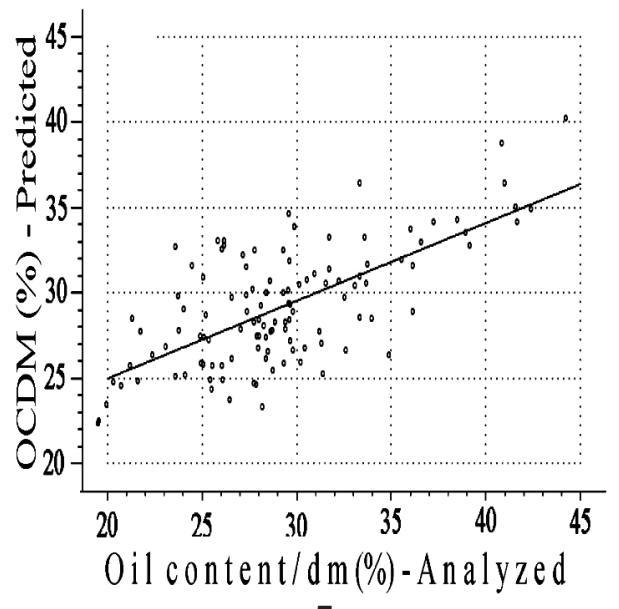

5

Figure 1.

Olive quality parameters predictions

Free acidity of olive oil (1) and oil yield (2) from Picual (Set A); Fruit moisture(3), oil content refered to fruit fresh weight (4), oil content refered to dry matter (5) from Picual (Set B).

were not higher than those obtained using the full spectrum. The calibration model for the prediction of $Y$ by the Abencor system without any pretreatment of the acquired spectral data showed the best results, represented in Figure 1.
The performance of the calibration obtained presented coeficients $R_{C}=0.86$ and $R_{C V}=0.83$ respectively (Table 2); RMSEC and SEC were $7.8 \%$ and $2.9 \%$. These ratios mean a good predictive potential of $Y$ using this technique. 
Table 2

Coefficients of model performance and external validation ${ }^{\text {a }}$

\begin{tabular}{|c|c|c|c|c|c|c|c|c|c|c|}
\hline \multicolumn{11}{|c|}{ CALIBRATIONS WITH ONLY INTERNAL VALIDATION } \\
\hline & Outliers & $\mathbf{R}_{\mathrm{C}}$ & $\mathbf{R}_{\mathrm{cv}}$ & RMSEC & SEC & Biass & & & & \\
\hline FA & 5 & 0.887 & 0.805 & 0.032 & 0.033 & $-2,5310^{-9}$ & & & & \\
\hline Y & 3 & 0.859 & 0.831 & 1.570 & 0.590 & $-3,1810^{-7}$ & & & & \\
\hline & 2 & 0.914 & 0.884 & 1.639 & 1.646 & $-1,0310^{-6}$ & & & & \\
\hline $\mathrm{OCFW}_{\mathrm{B}}$ & 4 & 0.733 & 0.634 & 3.478 & 3.493 & $3,1710^{-7}$ & & & & \\
\hline $\mathrm{OCDM}_{\mathrm{B}}$ & 9 & 0.570 & 0.297 & 5.768 & 5.794 & $-1,6110^{-6}$ & & & & \\
\hline & 2 & 0.999 & 0.593 & 0.016 & 0.016 & $-6,3610^{-7}$ & & & & \\
\hline $\mathrm{OCFW}_{\mathrm{C}}$ & 1 & 0.818 & 0.522 & 0.265 & 0.275 & $7,3310^{-7}$ & & & & \\
\hline $\mathrm{OCDM}_{\mathrm{C}}$ & 2 & 0.999 & 0.804 & 0.018 & 0.019 & $3,1810^{-7}$ & & & & \\
\hline \multicolumn{11}{|c|}{ CALIBRATIONS WITH EXTERNAL VALIDATION } \\
\hline & Outliers & $\mathbf{R}_{\mathrm{C}}$ & $\mathbf{R}_{\mathrm{cv}}$ & RMSEC & SEC & Biass & RMSEP & SEP & & \\
\hline FA & 8 & 0.896 & 0.771 & 0.025 & 0.026 & $-1,1510^{-8}$ & 0.05 & 22.6 & 0.05 & 22.6 \\
\hline$M_{B}$ & 1 & 0.943 & 0.895 & 1.189 & 1.196 & $-4,2910^{-7}$ & 1.52 & 2.5 & 1.55 & 2.6 \\
\hline $\mathrm{OCFW}_{\mathrm{B}}$ & 10 & 0.856 & 0.625 & 1.546 & 1.557 & $-7,0810^{-7}$ & 7.98 & 23.5 & 5.40 & 15.9 \\
\hline $\mathrm{OCDM}_{\mathrm{B}}$ & 10 & 0.837 & 0.605 & 3.245 & 3.266 & $-9,8510^{-6}$ & 12.3 & 21.9 & 8.20 & 14.6 \\
\hline
\end{tabular}

FA, Free acidity, Set $A ; Y$, Oil yield, Set $A ; M_{B}$, Fruit moisture, Set $B ; M_{C}$, Fruit moisture, Set $C ; O_{C F}$, Oil content refered to fresh weight, Set B; OCDM $\mathrm{B}_{\mathrm{B}}$, Oil content refered to dry matter, Set B; OCFW dry matter, Set C. Set A, Set B and Set C: sets of olive fruit samples.

\subsection{Fruit Moisture-Set B}

The best result in the calibrations for $M_{B}$ prediction presented $R_{C}=0.91$, being $R_{C V}=0.88$. These results were obtained with absorbance spectral data mean normalized. Figure 1 represents the dispersion of the prediction obtained with this model compared to the values of the reference method of analysis used, by drying the entire fruits in a stove. The model statistical ratios are shown in Table 2.

An external validation exercise using samples completely independent from those used in the calibration was carried out. For this purpose, a calibration with $3 / 4$ of the total number of samples was developed and used to predict $M$ in the rest of the samples (1/4). The statistical coefficients of calibration and prediction are included in Table 2. The predictive error obtained, expressed by the RMSEP, accounted for $2.5 \%$ of the average humidity of the validation set, the standard error of operation SEP was $2.6 \%$. These results show very good potential of the art, including methodology and reference analysis for predicting $\mathrm{M}$.

\subsection{Oil content Referred to Fresh Weight-Set B}

In the calibrations for the prediction of the oil content regarding olive fresh weight $\left(\mathrm{OCFW}_{\mathrm{B}}\right)$, the best return was obtained without any spectral data processing, reaching calibration coefficients $\mathrm{R}_{\mathrm{C}}=$ 0.73 and $R_{\mathrm{CV}}=0.63$ (Table 2). The dispersion of the prediction obtained compared with the corresponding analytical values is expressed in Figure 1.
External validation was conducted using a different calibration, obtained from 90 of the 120 samples, and the prediction of $\mathrm{OCFW}_{\mathrm{B}}$ for the remaining samples was later obtained. The coefficient of calibration $\left(R_{c}=0.86\right)$ was higher than that obtained with all the samples, although the full-cross validation result was somewhat lower. The statistical coefficients of calibration and prediction are included in Table 2.

\subsection{Oil Content Referred to Dry Matter-Set B}

The best result in the prediction of oil content regarding dry olive matter $\left(\mathrm{OCDM}_{\mathrm{B}}\right)$ was achieved after trying various combinations of chemometric treatments by using absorbance spectral data, mean normalization and then applying first the Savitzky-Golay derivative. Figure 1 provides the dispersion of prediction with the calibration achieved. Table 2 includes statistical coefficients.

External validation exercises were carried out. Table 2 includes the statistical coefficients of the calibration developed for this purpose as well as the external validation, which were similar to those values in the $\mathrm{OCFW}_{\mathrm{B}}$ prediction.

\subsection{Fruit Moisture Test-Set C}

The treatment of spectral data provided a better functioning of the calibration test because of its transformation into absorbance, mean normalization and first Savitzky-Golay derivative. Figure 2 represents the dispersion of predicting $M_{c}$ compared with the corresponding values obtained using the Soxhlet method. As shown in Table 2, the resulting $R_{C}$ was very high, although $R_{C V}=0.59$, did not indicate an optimal validation. 


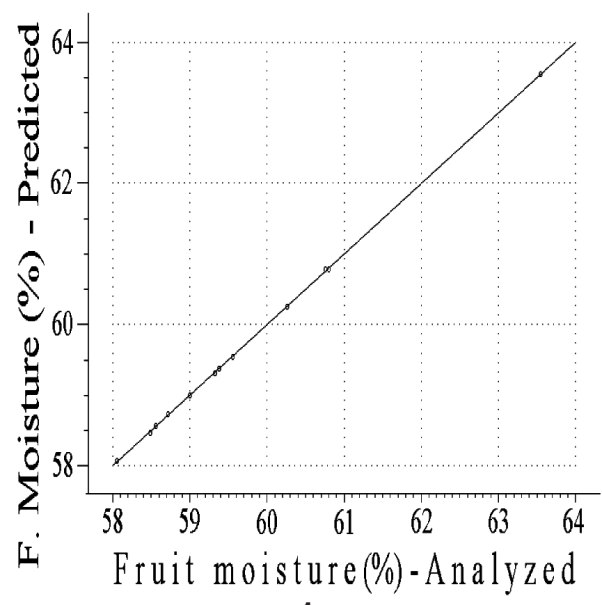

1

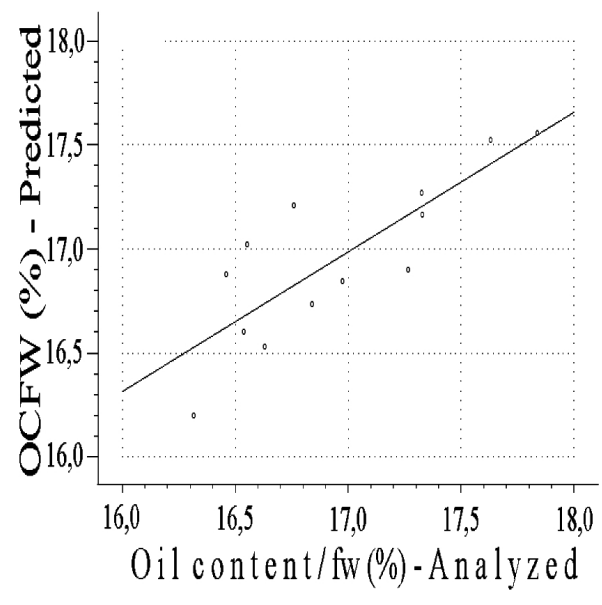

2

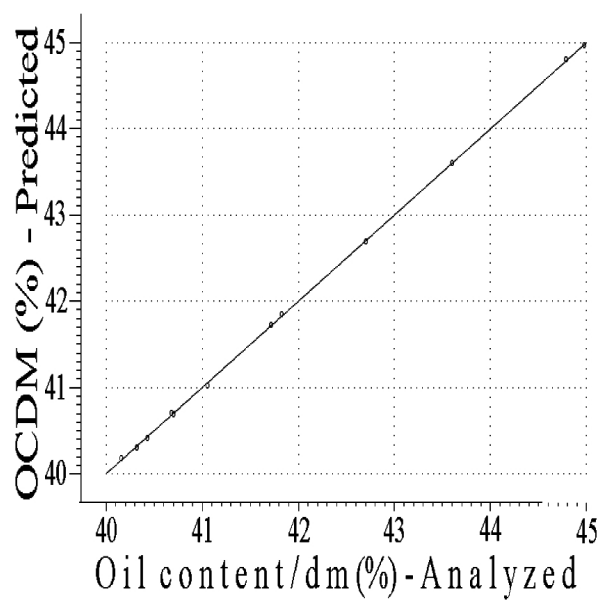

3

Figura 2

Olive quality parameters predictions with Soxhlet method.

Fruit moisture (1), oil content refered to fresh weight (2), oil content refered to dry matter (3) (Set C).

The limited number of samples made it impossible to conduct external validation exercises. However, the good behavior of the model shown in Figure 2, where the dispersion of the prediction is depicted, encourages expansionin the future of this calibration with a larger number of samples.

\subsection{Oil Content Refered to Fresh Weight Test- Set C}

As in the predictive calibration test of $\mathrm{M}_{\mathrm{C}}$, the best results were obtained with spectral data in absorbance, mean normalized and applying first Savitzky-Golay derivative. Figure 2 shows the dispersion of the prediction. If we compare the functioning of this predictive model with that obtained from the hexane:isopropanol extraction, it appears that for this parameter, with calibration coefficients $R_{C}=0.82$ and $R_{C V}=0.52$ (Table 2), the results reached with both reference methods were analogous.

\subsection{Oil Content Refered to Dry Matter Test- Set C}

Likewise for this calibration test, the best treatment of the spectral data was conversion to absorbance, mean normalization and first SavitzkyGolay derivative. Figure 2 shows the dispersion of the prediction of $\mathrm{OCDM}_{\mathrm{C}}$ with the calibration developed. The coefficient of calibration achieved was very high; although the $R_{C v}$ value as reflected in Table 2 was lower, the goodness of the coefficients RMSEC and SEC, both of $0.04 \%$, indicates that, as in the case of moisture prediction, good predictive models of $\mathrm{OCDM}_{\mathrm{C}}$ can be achieved using the Soxhlet method as reference analysis.

\section{CONCLUSIONS}

Fruit moisture predictions carried out with the predictive models reached from different 
methodologies either using olive paste or the whole olive fruit, gave accurate predictions of this parameter in both cases. This fact must be emphasized, since determining the olive milling parameters in the olive mill depends largely on the moisture content of the olive fruit.

The oil free acidity predictive model reached significantly good coefficients of calibration $\left(R_{C}\right)$ and full cross validation $\left(\mathrm{R}_{\mathrm{CV}}\right)$, considering that acidity is a parameter of olive oil and not of the olive fruit. The RMSEP, however, was higher than desirable for an accurate prediction.

For oil yield, the coeficients $R_{C}$ and $R_{C V}$ indicated a good predictive potential of $Y$ using this technique. The prediction of oil content using hexane: isopropanol extraction reference analysis, both regarding fresh weight and dry matter did not reach the accuracy needed to be useful in practice. Nevertheless, the goodness of the model performance encouraged the improving of the turn out with new calibrations using this methodology. Better results were obtained with the calibrations conducted from Soxhlet extraction, but more research is needed.

\section{REFERENCES}

Bendini A, Cerretani L, Di Virgilio F, Belloni P, Lercker G, Gallina T. 2007. In process monitoring in industrial olive mill by means of FT-NIR. Eur. J. Lipid Sci. Technol. 109, 498-504.

Conte L, Brussolo G, Pizzale L, Carazzolo A, Meurens M, Pavan O. 2003. Application of near infrared reflectance analysis to olive oil production quality control. Riv. Ital. Sostanze Gr. 80(4), 213-217.

Costa AF, Coelho MJ, Gambarra FF, Bezerra SR, Harrop RK, Ugulino MC. 2008. NIR spectrometric determination of quality parameters in vegetable oils using PLS and variable selection. Food Res. Int. 41, 341-348.

Downey G, Mclntyre P, Davies AN. 2002. Detecting and quantifying sunflower oil adulteration in extra virgin olive oils from the eastern Mediterranean by visible and near-infrared spectroscopy. J. Agric. Food Chem. 50, 5520-5525.

Dull GG, Birth GS, Smittle DA, Leffler RG. 1989. Near Infrared Alaysis of soluble solids in iuntatc Cantaloupe. J. Food Sci. 54, 393-395.

Dull GG, Leffler RG, Birth A, Smittle A. 1992. Instruments for non-destructive measurement of soluble solids in honeydew melons. Transactions of the ASAE 35, 735737.

EUC. 1991. European Union Commission Regulation Characteristics of olive and olive Pomace Oils. Off $J$ Eur Communities. Anexe IX.

EUC1997. European Union Commission Regulation № 2472/97, amending the Regulation $n^{\circ} 2568 / 91$. Off $J$ Eur Communities.

Galtier O, Dupuy N, Le Dr'eau Y, Ollivier D, Pinatel C, Kister J, Artaud J. 2007. Geographic origins and compositions of virgin olive oils determinated by chemometric analysis of NIR spectra. Anal. Chim. Acta 595, 136-144.

Gallardo L, Osorio E, Sanchez J. 2005. Application of near infrared spectroscopy (NIRS) for the real-time determination of moisture and fat contents in olive pastes and wastes of oil extraction. Alimentación Equipos y Tecnologia 24(206), 85-89.

García A., Ramos N, Ballesteros E. 2005. Estudio comparativo de distintas técnicas analíticas (espectroscopía de NIR y RMN y extracción mediante Soxhlet) para la determinación del contenido graso y de humedad en aceitunas y orujo de Jaén. Grasas y Aceites 56, 220-227.

García JM, Seller S, Pérez-Camino MC. 1996. Influence of fruit ripening on olive oil quality. J. Agric. Food Chem. 44, 3516-3520.

Guthrie JA, Liebensberg CJ, Walsh KB. 2006. NIR model development and robutness in prediction of melon fruit total soluble solids. Australian J. Agric. Res. 57, 411-418.

Guthrie JA, Walsh KB, Reid DJ, Liebensberg CJ. 2005. Assesment of internal quality attributes of mandarin fruit. 1. NIR calibration model development. Australian J. Agric. Res. 56, 405-416.

Hermoso M, Uceda M, Garcia S, Jimenez A, Beltrán G. 1999. Preliminary Results of Nir "On-Line" Measure Of Oil Content And Humidity In Olive Cakes From The Two Phases Decanter. ISHS Acta Horticulturae 474: III International Symposium on Olive Growing.

Hernández A, He Y, García A. 2006. Non-destructive measurement of acidity, soluble solids and firmness of Satsuma mandarin using vis/NIR-spectroscopy techniques. J. Food Engin. 77, 313-319.

Hernández N, Lurol S, Roger JM, Bellon-Maurel V. 2003. Robutness of models based on NIR spectra for sugar content prediction in apples. J. Near Infrared Spec. 11, 97-107.

Ito $\mathrm{H}$, Morimoto S, Yamuchi R, Ippoushi K, Azuma K, Higashio H. 2002. Potential of near infrared spectroscopy for non-destructive estimation of soluble solids in watermelons. In Proceedings of the Second International Symposium on Cucurbits, Tsukuba, Japan, 28 September to 1 October 2001. Acta Horticulturae 588, 353-356.

lyo C, Kawano S. 2001. [Predicting Brix values of stored apples using near infrared spectra]. J. Japanesse. Soc. Hort. Sci. 70, 510-515.

Jiménez A, Molina A, Pascual MI. 2005. Using optical NIR sensor for on-line virgin olive oils characterization. Sensors and Actuators B 107, 64-68.

Kawano S, Fujiwara T, Iwamoto MJ. 1993. Nondestructive determination of sugar content in Satsuma mandarin using near infrared (NIR) transmittance. J. Japanesse Soc. Hort. Sci. 62, 465-470.

León L, Rallo L, Garrido A. 2003. Análisis de aceituna intacta mediante espectroscopia en el infrarrojo cercano (NIRS): una herramienta de utilidad en programas de mejora de olivo. Grasas y Aceites 54, 41-47.

Leon L, Garrido A, Downey G. 2004. Parent and Harvest Year Effects on Near-Infrared Reflectance Spectroscopic Analysis of Olive (Olea europaea L.) Fruit Traits. J. Agric. Food Chem. 52, 4957-4962.

Lu R. 2001. Predicting firmness and sugar content of sweet cherries using near infrared diffuse reflectance spectroscopy. Transactions of the ASAE 44, 1265-1271.

Mailer RJ. 2004. Rapid Evaluation of Olive Oil Quality by NIR Reflectance Spectroscopy. JAOCS 81, 823-827.

Nicolaï BM, Beullens K, Bobelyn E, Peirs A, Saeys W, Theron K, Lammertyn J. (2007). Nondestructive measurement of fruit and vegetable quality by means of NIRS spectroscopy: A review. Postharvest Biol. Technol. 46, 99-118. 
McClure W.F. 2003. Review. 204 years of near infrared technology: 1800-2003. J. Near Infrared Spec. 11, 487-518.

Muik B, Lendl B, Molina A, Perez L, Ayora MJ. 2004. Determination of oil and water content in olive pomace using near infrared and Raman spectrometry. A comparative study. Anal. Bioanal. Chem.) 379, 35-41

Peiris KHS, Dull GG, Leffler RG, Kays SJ. 1997. Nondestructive determination of soluble solids content of peach by near infrared spectroscopy. Sensors for Nondestructive Testing. Measuring the Quality of Fresh Fruits and Vegetables. Proceedings from the Sensors for Nondestructive Testing International Conference and Tour Holiday Inn International Drive Resort. Orlando, Florida.

Slaughter DC. 1992. Near infrared analysis of soluble solids in peaches. 1992 Summer Meeting, Charlotte, North Carolina, paper no 92-7056, American Society of Agricultural Engineers, 2950 Niles Rd, St Joseph, MI 49085-9659 USA.

Tsuchikawa S, Sakai E, Inoue K. 2003. Application of Time-of-flight Near-infrared Spectroscopy to detect sugar and acid content in Satsuma mandarin. J. Amer. Soc. Hort. Sci. 128, 391-396.

Wesley IJ, Barnes RJ, McGill AEJ. 1995. Measurement of Adulteration of Olive Oils by Near-Infrared Spectroscopy. JAOCS 72, 289-292.

Wold S, Martens H, Wold H. 1983. The Multivariate Calibration Problem in Chemistry solved by the PLS method. In Lecture notes in Mathematics, Springer Verlag, Heidelberg, pp 286-293.

Yang H, Irudayaraj J. 2001. Comparison of NearInfrared, Fourier Transform-Infrared, and Fourier Transform-Raman Methods for DeterminingOlive Pomace Oil Adulteration in Extra Virgin Olive Oil. JAOCS 78, 889-895.

Zude M, Herold B, Roger JM, Bellon-Maurel V, Landahl S. 2006. Non destructive tests on the prediction of apple fruit flesh firmness and soluble solids content on tree and in shelf life. J. Food Engin. 77, 254-260. 